\title{
Dynamics of endemic infectious diseases of animal and human importance on three dairy herds in the northeastern United States
}

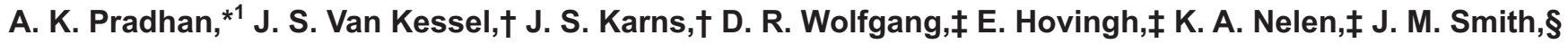 \\ R. H. Whitlock,\# T. Fyock,\# S. Ladely, || P. J. Fedorka-Cray, \| and Y. H. Schukken* \\ ${ }^{*}$ Quality Milk Production Services, Department of Population Medicine and Diagnostic Sciences, College of Veterinary Medicine, \\ Cornell University, Ithaca, NY 14850 \\ †Environmental Microbial Safety Laboratory, ANRI, USDA-ARS, Beltsville, MD 20705 \\ ‡Department of Veterinary and Biomedical Science, Pennsylvania State University, University Park 16802 \\ $\S$ Department of Animal Science, University of Vermont, Burlington 05405 \\ \#New Bolton Center, Department of Clinical Studies, School of Veterinary Medicine, University of Pennsylvania, Kennett Square 19348 \\ ||Russell Agricultural Research Center, USDA-ARS, 950 College Station Road, Athens, GA 30605
}

\begin{abstract}
Endemic infectious diseases in dairy cattle are of significant concern to the industry as well as for public health because of their potential impact on animal and human health, milk and meat production, food safety, and economics. We sought to provide insight into the dynamics of important endemic infectious diseases in 3 northeastern US dairy herds. Fecal samples from individual cows and various environmental samples from these farms were tested for the presence of major zoonotic pathogens (i.e., Salmonella, Campylobacter, and Listeria) as well as commensal bacteria Escherichia coli and enterococci. Additionally, the presence of Mycobacterium avium ssp. paratuberculosis was tested in fecal and serum samples from individual cows. Test results and health and reproductive records were maintained in a database, and fecal, plasma, DNA, and tissue samples were kept in a biobank. All bacteria of interest were detected on these farms and their presence was variable both within and between farms. The prevalence of Listeria spp. and L. monocytogenes in individual fecal samples within farm A ranged from 0 to $68.2 \%$ and 0 to $25.5 \%$, respectively, over a period of $3 \mathrm{yr}$. Within farm B, continuous fecal shedding of Salmonella spp. was observed with a prevalence ranging from 8 to 88\%; Salmonella Cerro was the predominant serotype. Farm C appeared less contaminated with Salmonella and Listeria, although in the summer of 2005, 50 and $19.2 \%$ of fecal samples were positive for Listeria and L. monocytogenes, respectively. The high prevalence of E. coli (89 to 100\%), Enterococcus (75 to 100\%), and Campylobacter (0 to 81\%) in feces suggested they were ubiquitous throughout the farm environment. Fecal culture and ELISA results indicated a low prevalence
\end{abstract}

Received June 25, 2008.

Accepted November 13, 2008.

${ }^{1}$ Corresponding author: akp49@cornell.edu of Mycobacterium avium ssp. paratuberculosis infection in these farms (0 to $13.6 \%$ and 0 to $4.9 \%$ for culturepositive and ELISA-positive, respectively), although the occasional presence of high shedders was observed. Results have major implications for food safety and epidemiology by providing a better understanding of infectious disease dynamics on dairy farms. Comprehensive understanding of these infections may lead to better farm management practices and pathogen reduction programs to control and reduce the on-farm contamination of these pathogens and to prevent their further entry into the food-chain.

Key words: infection dynamics, dairy herd, longitudinal study, epidemiology and food safety

\section{INTRODUCTION}

Infectious diseases are of increasing concern on dairy farms because of their potential impact on animal and human health, milk and meat production, food safety, and economics. Dairy farms are recognized as important reservoirs of foodborne pathogens. Isolation of bacterial pathogens with similar biotypes from dairy farms and from outbreaks of human disease substantiates the hypothesis of a constantly maintained reservoir of foodborne pathogens in the dairy environment that can affect humans by direct contact, ingestion of beef, raw contaminated milk and cheese, or cross-contamination during processing of milk products (Oliver et al., 2005). Although common infectious diseases such as bovine viral diarrhea, bovine rhinotracheitis, and contagious mastitis typically do not pose human health threats, some diseases found in dairy animals are caused by zoonotic pathogens (i.e., salmonellosis, campylobacteriosis, listeriosis) or potentially zoonotic pathogens (i.e., Johne's disease; Grant, 2005). Dairy cattle and their environment may harbor pathogens that pose potential human health hazards (Nam et al., 2004). 
Contamination of foods with pathogens such as Salmonella spp., Listeria monocytogenes, and Campylobacter spp. is a major public health concern worldwide as these pathogens can cause diseases with significant debilitating effects (Nam et al., 2004). Ruminants are natural reservoirs of these microorganisms and frequently appear nonsymptomatic while shedding these bacteria into the environment (Gansheroff and O'Brien, 2000). Pathogens such as Salmonella can persist on dairy farms with few or no clinical manifestations (Van Kessel et al., 2007). Shedding of Salmonella occurs with the presence of clinical illness or in the absence of clinical signs (Edrington et al., 2004). Listeria monocytogenes is another bacterial pathogen that causes significant morbidity and mortality in humans and animals and can be shed in the fecal material of clinically infected animals; however, healthy animals can be latent carriers of L. monocytogenes (Borucki et al., 2004; Nightingale et al., 2004). Raw milk, meat, and raw foods of plant origin that were cross-contaminated by manure from infected or shedding animals represented direct links between infected humans and L. monocytogenes in farm animals and farm environments (Borucki et al., 2004; Nightingale et al., 2004). Healthy cattle may be reservoirs for several Campylobacter species such as Campylobacter jejuni and Campylobacter coli (Wesley et al., 2000; Harvey et al., 2004). Because of their increasing resistance to antibiotics, the commensal bacteria Escherichia coli (Lundin et al., 2008) and enterococci have become a focus of attention (Franz et al., 1999). Mycobacterium avium ssp. paratuberculosis (MAP), a slow-growing bacterial pathogen of ruminants, causes paratuberculosis (Johne's disease), an incurable chronic disease of ruminants (Gollnick et al., 2007), resulting in animal welfare and economic issues. On US dairy farms, herd-level prevalence of MAP infection based on serologic testing (ELISA) was at least $22 \%$, with a prevalence of at least $40 \%$ for herds over 300 animals (Wells and Wagner, 2000). Within each infected herd $<10 \%$ of animals typically test positive for MAP (Mitchell et al., 2008).

Zoonotic pathogens were isolated from dairy cattle and from various locations within dairy farm environments such as manure, water, feed, bird droppings, feral animals, flies, and bedding materials (Murinda et al., 2004; Van Kessel et al., 2007). Therefore, understanding the persistence of these organisms in dairy cattle and their environment is essential to understanding their sources, possible reservoirs, and further dissemination, and for evaluating on-farm control strategies. Food safety, animal health, and productivity have a common need for improved understanding of the herd-level dynamics of bacterial infection. Many investigations have focused on single point-in-time sampling or multiple samples over a short period of time on a large number of herds. The objective of this paper was to describe longitudinal sampling and provide insight into the dynamics of important endemic infectious diseases in 3 well-managed northeastern US dairy herds.

\section{MATERIALS AND METHODS}

\section{Description of the Research Program and Dairy Farms}

The dairy farms from which samples were collected participate in a multi-state research program conducted under a cooperative research project between the Regional Dairy Quality Management Alliance and the USDA-ARS. The Regional Dairy Quality Management Alliance comprises stakeholders in 10 states in the northeastern and mid-Atlantic areas of the United States and its mission is to ensure a healthful and safe food supply by advocating the adoption of Best Management Practices in northeast dairies. This project emphasizes longitudinal data collection of endemic infectious diseases of public health and animal health concern in dairy herds.

All data comprising information about farm management surveys, herd and cow level information such as laboratory test results, health and reproductive records was maintained in a database at Cornell University (Ithaca, NY). Biological samples were kept in a secure biobank at New Bolton Center, University of Pennsylvania, to allow for future research endeavors that require samples collected over the lifetime of cows in dairy herds with a known infectious status. This biobank contains a repository of well-characterized fecal and plasma replicates from each cow during each sampling time, DNA samples from each cow, and tissue samples from the culled cows. Bacterial isolates were stored indefinitely at each laboratory location.

Three commercial dairy farms participated in this study: farm A in New York State, farm B in Pennsylvania, and farm $\mathrm{C}$ in Vermont. Farms were chosen to represent dairy farms in their respective region and state. Each of these farms participated in the dairy quality assurance program in their state and had DHIA membership with monthly milk testing, Farm Animal Identification and Records implementation, and computerized on-farm disease recording. The milking herds consisted of approximately 330, 110, and 140 cows on farms A, B, and C, respectively. Farm stalls were fitted with comfort mattresses and bedded with bedding materials such as sand and wood products. Replacement animals were primarily from within the herd, although replacements were occasionally purchased. 


\section{Sampling, Sample Collection, and Sample Handling}

Sampling commenced in February, March, and November 2004 on farms A, B, and C, respectively. The project design included biannual collection of individual fecal samples and quarterly collection of blood serum from all milking and nonlactating cows. Environmental samples were collected quarterly from several sources, including source water, water from drinking troughs of cows and heifers, standing water or slurry in freestall barns, feed from different pens of cows and calves, manure composites from milking cows, nonlactating cows, periparturient cows, and calf pens as well as the milking alleyways, calf bedding, corn silage, bird droppings, flies, and insects. Environmental sampling sites were mapped at the initial visit and, as much as possible, the same location was sampled over time. In special interest situations, sampling frequency was increased and more samples at shorter time intervals were collected; these samplings were identified as special samplings. For example, special samplings from the milking parlor, milking equipment, and other environmental sources were done from farm A to track the source of Listeria contamination, as the milking equipment appeared contaminated with Listeria. Similarly, the occurrence of salmonellosis on farm B prompted more intensive sampling of environmental sources and individual cows for fecal samples to track the course of the outbreak (Van Kessel et al., 2007).

Fecal samples were collected directly from the rectum using individual disposable gloves and were aseptically transferred into sterile vials $(50-\mathrm{mL}$ plastic tube, BD Falcon propylene screw top, BD Biosciences, San Jose, CA). After collection, fecal tubes labeled with the corresponding sample numbers were placed into large $\mathrm{Zi}$ ploc bags (approximately 20 fecal tubes into each bag), which were then placed into coolers with ice packs. Environmental samples were collected in sterile containers that were appropriate for the sample such as Whirl-Pak bags (Nasco, Ft. Atkinson, WI) for feed samples, centrifuge tubes for fecal slurry (BD Biosciences), and sterile bottles $(500 \mathrm{~mL}$ or $1 \mathrm{~L})$ for water samples. On farm A, during special samplings from the milking parlor, samples were collected using a Bacti-Sponge kit (Hardy Diagnostics, Santa Maria, CA) dampened with $10 \mathrm{~mL}$ of neutralizing buffer (Difco, BD Diagnostics, Sparks, MD) and sterile cotton swabs. Two full blood tubes (2 heparin tubes) were collected from each cow using the tail vein. The blood samples were placed in test tube racks, double wrapped in plastic wrap, and packed in the cooler with ice packs.

All coolers containing collected samples were transported overnight to the 3 laboratories for further analysis. Fecal and environmental samples were sent to the
Environmental Microbial Safety Laboratory of the ARS (Beltsville, MD) and the Bacterial Epidemiology and Antimicrobial Resistance laboratory of Russell Research Center (Athens, GA) for testing of foodborne pathogens such as Salmonella, Listeria, and Campylobacter, as well as the commensal bacteria, generic E. coli, and Enterococcus. Blood and fecal samples were sent to the Johne's Research Laboratory (New Bolton Center at the University of Pennsylvania) for MAP testing.

\section{Microbial Analysis}

For detection of Salmonella and Listeria spp., upon arrival at the Environmental Microbial Safety Laboratory, approximately $25 \mathrm{~g}$ of feces or composite manure sample was weighed into a filtered stomacher bag (GSI Creos Corporation, Tokyo, Japan), diluted (2:1, wt/ wt) with $1 \%$ buffered peptone water (BPW) and pummeled in an automatic bag mixer (BagMixer, Interscience Laboratories Inc., Weymouth, MA) for 2 min. Typically, larger aliquots of feed samples (40 to $60 \mathrm{~g}$ ) were used and when the samples were of low moisture content, larger volumes of BPW were required for extraction. For detection of E. coli, Enterococcus, and Campylobacter at the Bacterial Epidemiology and Antimicrobial Resistance laboratory, 1-g fecal samples were diluted 1:9 (wt/vol) in sterile PBS $(0.1 M, \mathrm{pH}$ 7.2), and $100-\mu \mathrm{L}$ aliquots were inoculated into selective enrichment media. For feed samples, $10 \mathrm{~g}$ was placed in a Whirl-Pak bag into which $90 \mathrm{~mL}$ of $1 \times$ BPW was added and incubated at $37^{\circ} \mathrm{C}$ for $24 \mathrm{~h}$. For water, 100 $\mathrm{mL}$ of $10 \times \mathrm{BPW}$ was added to $900 \mathrm{~mL}$ of sampled water and incubated at $37^{\circ} \mathrm{C}$ for $24 \mathrm{~h}$.

Listeria spp. Fecal samples were collected from all cows; however, microbial analysis for Listeria was done on approximately every fifth randomly selected fecal sample for most of the samplings. In some cases microbial testing was done for all fecal samples collected. For enrichment of Listeria spp., $5 \mathrm{~mL}$ of fecal filtrate was added to $5 \mathrm{~mL}$ of double-strength modified Listeria enrichment broth (BD Diagnostics). Water $(250 \mu \mathrm{L})$ was plated in triplicate directly onto modified Oxford medium (MOX) agar (Difco Laboratories, Detroit, MI) using an Autoplate 4000 spiral-plater (Spiral Biotech, Gaithersburg, MD). Plates were incubated at $37^{\circ} \mathrm{C}$ and scored for presumptive Listeria spp. colonies (esculin hydrolysis; dimpled, flat, silver colonies) at 24 and 48 h. For enrichment of Listeria, water $(100 \mathrm{~mL})$ was filtered through sterile $0.45-\mu \mathrm{m}$ cellulosic filters $(47 \mathrm{~mm}$; Osmonics Inc., Westborough, MA) with suction, and the filters were placed in $10 \mathrm{~mL}$ of modified Listeria enrichment broth (BD Diagnostics).

For all samples, enrichment tubes were incubated at $37^{\circ} \mathrm{C}$ for $48 \mathrm{~h}$ and the enriched broth was streaked 
$(10 \mu \mathrm{L})$ onto MOX (BD Diagnostics). Cycloheximidesupplemented MOX $(50 \mu \mathrm{g} / \mathrm{mL}$; C-MOX) was used for fecal samples to inhibit fungal growth. Plates were incubated at $37^{\circ} \mathrm{C}$ and scored for presumptive Listeria colonies as above at 24 and $48 \mathrm{~h}$. Isolated, presumptive Listeria colonies were patched (biomass transfer) from MOX or C-MOX plates onto MOX, polymyxin acriflavin lithium-chloride ceftazidime esculin mannitol (PALCAM, BD Diagnostics), trypticase soy agar with $0.6 \%$ yeast extract, and a chromogenic plating medium, BCM Listeria (Biosynth International Inc., Naperville, IL). Colonies that exhibited the Listeria phenotype (as described above on MOX, gray-green with esculin hydrolysis on PALCAM) were preserved for future analysis. Colony biomass was transferred from the PALCAM plates to $1.5 \mathrm{~mL}$ of tryptic soy broth and incubated at $37^{\circ} \mathrm{C}$ for $48 \mathrm{~h}$. The culture was centrifuged $(16,000 \times g)$ and the supernatants were discarded. The bacterial pellet was resuspended in 0.5 $\mathrm{mL}$ of $1 \times$ freezing medium, and the isolates were stored at $-80^{\circ} \mathrm{C}$. Hemolytic activity of select presumptive $L$. monocytogenes isolates (blue colonies on BCM Listeria) was determined by stabbing blood agar (Columbia with $5 \%$ sheep blood; Remel, Lenexa, KS) and incubating at $37^{\circ} \mathrm{C}$ for $48 \mathrm{~h}$. The Christie, Atkins, Munch-Peterson test was performed on select isolates using Staphylococcus aureus Beta Lysin Disks (Remel) and Rhodococcus equi (ATCC 6939; American Type Culture Collection, Manassas, VA) on sheep blood agar.

Salmonella. For enrichment of Salmonella, $5 \mathrm{~mL}$ of fecal filtrate was added to $5 \mathrm{~mL}$ of double-strength tetrathionate broth (BD Diagnostics). For all samples, enrichment tubes were incubated at $37^{\circ} \mathrm{C}$ for 18 to $24 \mathrm{~h}$ after which $10 \mu \mathrm{L}$ of the broth was streaked onto xylose lysine tergitol 4 (XLT4) agar (XLT4 agar base with XLT4 supplement, BD Diagnostics). Plates were incubated at $37^{\circ} \mathrm{C}$ and scored at 24 and $48 \mathrm{~h}$ for presumptive Salmonella (black colonies). Isolated, presumptive Salmonella colonies (at least 6 randomly chosen isolates per sample) were transferred from XLT4 plates onto XLT4, brilliant green, and L-agar (Lennox broth base with 1.5\% agar; Gibco Laboratories, Long Island, NY) and incubated at $37^{\circ} \mathrm{C}$ for $24 \mathrm{~h}$. Colonies that exhibited the Salmonella phenotype (black on XLT4 and pink on brilliant green agar) were preserved for future analysis. The isolates were stored at $-80^{\circ} \mathrm{C}$. Water samples were filtered $(100 \mathrm{~mL})$ through sterile $0.45-\mu \mathrm{m}$ cellulosic filters (47 mm; Osmonics Inc.) and filters were placed in $10 \mathrm{~mL}$ of tetrathionate broth and incubated for 18 to $24 \mathrm{~h}$ at $37^{\circ} \mathrm{C}$. Enrichments were streaked and preserved as above. Water samples were directly spiralplated $(250 \mu \mathrm{L})$ onto XLT4 agar using an Autoplate 4000 spiral-plater (Spiral Biotech), incubated at $37^{\circ} \mathrm{C}$, and scored at 24 and $48 \mathrm{~h}$ for Salmonella as above.
Salmonella isolates were serotyped as described previously (Van Kessel et al., 2007). Briefly, in the initial phases of the study, Salmonella isolates were sent to the National Veterinary Services Laboratories (Ames, IA) for serotyping. Once the herd prevalence rate increased to $>40 \%$, isolate serotypes were determined with repetitive sequence-based PCR using the enterobacterial repetitive intergenic consensus primers. An isolate with an enterobacterial repetitive intergenic consensus-PCR pattern that was similar to a pattern of an isolate serotyped by National Veterinary Services Laboratories was considered of that serotype.

E. coli, Enterococcus spp., and Campylobacter. Microbial analysis for these microorganisms was done on approximately every randomly selected fourth fecal sample. For E. coli detection, $100-\mu \mathrm{L}$ aliquots of fecal dilutions (1:9 wt/vol, in PBS) and $100-\mu \mathrm{L}$ aliquots of other enriched samples (in BPW) were streaked for isolation onto CHROMagar EEC (Hardy Diagnostics, Santa Maria, CA) plates. The plates were incubated for 18 to $24 \mathrm{~h}$ at $37^{\circ} \mathrm{C}$. For detection of Enterococcus, 100$\mu \mathrm{L}$ aliquots of fecal dilutions (1:9 wt/vol, in PBS) and $100-\mu \mathrm{L}$ aliquots of other enriched samples (in BPW) were inoculated into 24-well tissue culture plates (BD Biosciences) containing $1 \mathrm{~mL}$ of enterococcosel broth (BD Diagnostics) per well. The enrichment broth was incubated for 18 to $24 \mathrm{~h}$ at $37^{\circ} \mathrm{C}$, followed by streaking for isolation onto enterococcosel agar (BD Diagnostics). Isolates were identified by species using a multiplex PCR (Jackson et al., 2004). For Campylobacter spp., 100- $\mu \mathrm{L}$ aliquots of fecal dilutions (1:9 wt/vol, in PBS) and 100$\mu \mathrm{L}$ aliquots of other enriched samples (in BPW) were inoculated into 24-well tissue culture plates (BD Biosciences) containing $1 \mathrm{~mL}$ of Bolton broth enrichment media (BD Diagnostics) per well. The enrichment broth was incubated for 36 to $48 \mathrm{~h}$ at $42^{\circ} \mathrm{C}$ under microaerobic conditions $\left(5 \% \mathrm{O}_{2}, 10 \% \mathrm{CO}_{2}\right.$, and $\left.85 \% \mathrm{~N}_{2}\right)$, followed by streaking for isolation onto Campy-Cefex agar plates (Stern et al., 1992). Agar plates were incubated for 36 to $48 \mathrm{~h}$ at $42^{\circ} \mathrm{C}$ under microaerobic conditions (as described above). Presumptive Campylobacter colonies were selected by observation of cellular morphology and motility using a wet mount under phase-contrast microscopy. Isolates were identified by species using a commercial multiplex PCR (BAX PCR, DuPont Qualicon, Wilmington, DE). For E. coli, Enterococcus, and Campylobacter isolation, environmental samples other than manure composites were enriched in BPW (1:9 wt/vol, 18 to $24 \mathrm{~h}$ at $37^{\circ} \mathrm{C}$ ) and then were struck for isolation onto CHROMagar EEC, enterococcosel agar, and Campy-Cefex, respectively. Agar plates were incubated as described for fecal samples.

$\boldsymbol{M A P}$. Upon receipt at the laboratory, blood tubes were centrifuged for $10 \mathrm{~min}$ at $900 \times g$ and the plasma 
was separated. Harvested plasma was placed in three 1.5-mL screw capped vials (with a rubber O-ring seal) labeled with farm identification, cow identification, and collection date and stored in a $-20^{\circ} \mathrm{C}$ freezer or stored in a refrigerator for up to $3 \mathrm{~d}$ when they could not be processed immediately. Stored plasma samples were taken from the freezer and allowed to come to room temperature before they were processed for ELISA testing. The sample vial was inverted several times to ensure complete mixing. Plasma samples were evaluated with the ParaCheck (Prionics USA Inc., La Vista, NE; formerly CSL/Biocor) ELISA to monitor serologic status of the cows.

For fecal samples, $2 \mathrm{~g}$ was placed in a $50-\mathrm{mL}$ plastic tube containing $35 \mathrm{~mL}$ of water (fecal-water tube). The contents were shaken vigorously and placed on a mechanical shaker for a minimum of $30 \mathrm{~min}$. Following mixing, the sample was allowed to stand at room temperature for $30 \mathrm{~min}$. A 5-mL sample from the top portion of the fecal-water tube was transferred to a second $50-\mathrm{mL}$ plastic centrifuge tube containing $25 \mathrm{~mL}$ of $0.9 \%$ hexadecylpyridinium chloride in half-strength brain heart infusion broth solution (final concentration of hexadecylpyridinium chloride $=0.75 \%$ ). Next, tubes were incubated at 35 to $37^{\circ} \mathrm{C}$ for 18 to $24 \mathrm{~h}$ (decontamination or germination step). Following the germination, tubes were centrifuged for $30 \mathrm{~min}$ at 900 $\times g$, the supernatant was discarded, and the pellet was resuspended by adding $1 \mathrm{~mL}$ of antibiotic brew $(1 \mathrm{~L}$ of half-strength brain heart infusion broth, $18.5 \mathrm{~g} / \mathrm{L}$; amphotericin B, $50 \mathrm{mg} / \mathrm{L}$; nalidixic acid, $100 \mathrm{mg} / \mathrm{L}$; vancomycin, $100 \mathrm{mg} / \mathrm{L}$ ) followed by vortexing. In the next step (incubation step), the resuspended pellet was incubated overnight or up to a maximum of $3 \mathrm{~d}$ at 35 to $37^{\circ} \mathrm{C}$. Following incubation, 4 tubes of Herrold's egg yolk media [2 in-house and 2 commercial (BD Diagnostics)] were inoculated with $0.2 \mathrm{~mL}$ per tube and then incubated in a slanted position at $37^{\circ} \mathrm{C}$. The tubes were read every $2 \mathrm{wk}$ with the final reading at $16 \mathrm{wk}$. Slightly raised white-yellow colonies were evaluated for typical acid fastness and morphological appearance of MAP. Each culture with colony growth was subcultured for mycobactin dependency before reporting the culture positive for MAP.

\section{RESULTS}

\section{Listeria spp.}

The prevalence of Listeria spp. and L. monocytogenes in individual fecal samples on 3 farms is given in Table 1. The percentage of Listeria spp. and L. monocytogenes in all environmental samples is shown in Figure 1. Three out of 10 environmental samples (i.e., 2 barn water samples and 1 calf manure composite sample) were positive for Listeria spp. and L. monocytogenes during the first farm A sampling in February 2004. On the second sampling in June 2004, 6 samples (3 manure

Table 1. Prevalence ${ }^{1}$ of Listeria spp. and Listeria monocytogenes in fecal samples collected from dairy cows on 3 farms over the study period

\begin{tabular}{|c|c|c|c|c|c|}
\hline Farm & Sampling date & $\begin{array}{c}\text { Samples } \\
\text { collected }\left(\mathrm{n}_{\mathrm{c}}\right)^{2}\end{array}$ & $\begin{array}{l}\text { Samples } \\
\text { tested }\left(n_{\mathrm{t}}\right)^{3}\end{array}$ & Listeria spp. & Listeria monocytogenes \\
\hline \multirow[t]{5}{*}{ A } & 17-Feb-2004 & 308 & 72 & 25.0 & 4.2 \\
\hline & 5-Oct-2004 & 326 & 65 & 0.0 & 0.0 \\
\hline & 3 -Oct-2005 & 308 & 63 & 7.9 & 1.6 \\
\hline & 1-May-2006 & 327 & 327 & 20.5 & 3.7 \\
\hline & 9-Oct-2006 & 333 & 0 & $\mathrm{NA}^{4}$ & NA \\
\hline \multirow{5}{*}{ B } & 6-Jun-2005 & 111 & 111 & 0 & 0.0 \\
\hline & 4-Dec-2005 & 108 & 0 & NA & NA \\
\hline & 5-Jun-2006 & 104 & 1 & 0 & 0.0 \\
\hline & 4-Dec-2006 & 103 & 0 & NA & NA \\
\hline & 5-Jun-2007 & 111 & 0 & NA & NA \\
\hline $\mathrm{C}$ & 15-Nov-2004 & 125 & 26 & 0.0 & 0.0 \\
\hline
\end{tabular}

${ }^{1}$ Prevalence is calculated as the number of positive samples divided by the number of samples tested $\left(\mathrm{n}_{\mathrm{t}}\right)$ expressed as percentage. The positive samples for Listeria spp. also include L. monocytogenes positive samples.

${ }^{2} \mathrm{n}_{\mathrm{c}}$ is the total number of individual fecal samples collected.

${ }^{3} \mathrm{n}_{\mathrm{t}}$ is the total number of samples used for microbial tests.

${ }^{4}$ Samples were not tested. 
composite, 1 feral fecal, 1 insect, and 1 standing water sample) were positive for Listeria spp. and 1 of these (feral fecal) was positive for $L$. monocytogenes. In a special sampling on June 29, 2004, 2 fly samples and 1 insect sample were collected, and all 3 were positive for Listeria spp., 1 of which (fly sample) was positive for L. monocytogenes (Figure 1). During a special farm A sampling in May 2007, samples were collected from a total of 40 sites from milking equipment, milk meters, teat cups and liners, milk filter, bulk tank, and different locations in the milking parlor and storage area including floors and drains. Listeria spp. was isolated from 14 sampling sites (35\%), 6 (15\%) of which were positive for L. monocytogenes.

The prevalence of targeted bacteria in different types of environmental samples collected from the dairy facilities on the 3 farms is presented in Table 2. The environmental samples from which Listeria spp. and L. monocytogenes were isolated in farm A included manure composites, drinking water from water troughs of heifer, lactating, and nonlactating cow pens, TMR, and flies. Listeria spp., including L. monocytogenes, were never detected in the farm source water on any of the 3 farms (Table 2). The prevalence of Listeria spp. and L. monocytogenes in drinking water on the 3 farms is greater than manure composites based on samples tested on each sample type (Table 2). On farm A, 61.7 and $29.8 \%$ of the total drinking water samples tested
( $\mathrm{n}=47$ ) were positive for Listeria spp. and L. monocytogenes, respectively. The prevalence of Listeria spp. and L. monocytogenes was 24.8 and $2.3 \%$, respectively, of the total manure composite samples tested $(\mathrm{n}=129)$ on farm A.

Environmental samples containing Listeria spp. and L. monocytogenes on farm B included manure composites, drinking water from different troughs, lactating cow concentrate (feed), and flies. The percentage of Listeria spp. and L. monocytogenes was 21.7 and 3.8\%, respectively, of the total drinking water samples tested ( $\mathrm{n}=106)$ on farm B. Of the total manure composites $(\mathrm{n}=224), 4$ and $0.9 \%$ were positive for Listeria spp. and L. monocytogenes, respectively, on farm B. On farm C, samples from which Listeria spp. and $L$. monocytogenes were detected included fecal droppings from feral animals, bird droppings, manure composites, and drinking water. Listeria spp. and L. monocytogenes were recovered from 74.3 and $17.1 \%$, respectively, of the total drinking water samples $(\mathrm{n}=35)$ on farm C. Listeria and L. monocytogenes-positive manure composites represented 8.3 and $0.6 \%$ of the total manure composite samples tested $(n=168)$ on farm C.

\section{Salmonella spp.}

The prevalence of Salmonella-positive fecal samples is in Table 3. During the first full herd sampling in

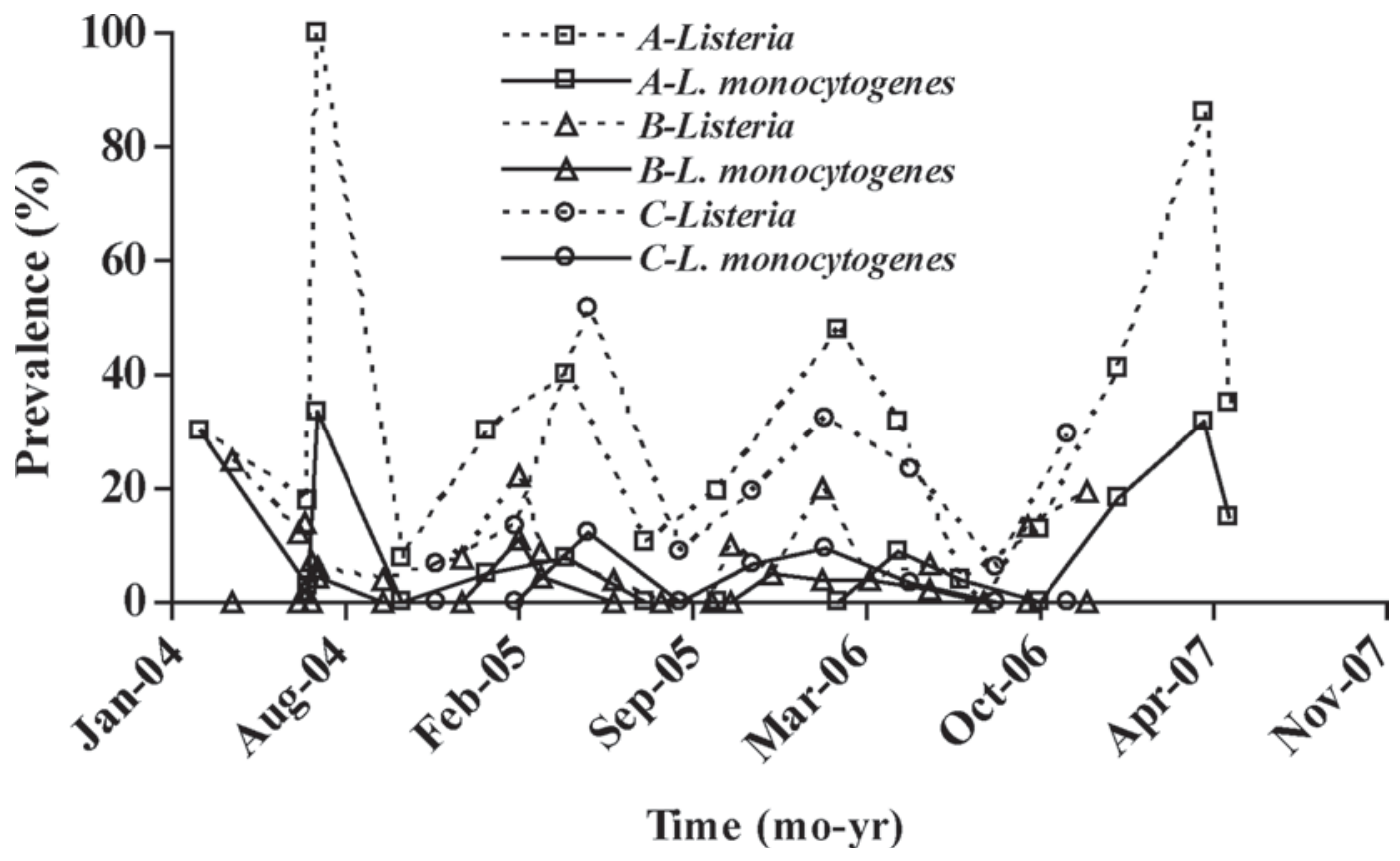

Figure 1. Prevalence of Listeria spp. and Listeria monocytogenes in environmental samples from 3 farms. The positive samples for Listeria spp. also include L. monocytogenes positive samples. A) farm A: total samples = 347 (including 40 samples on special sampling day, 16-May2007), average number of samples per sampling $=23$, study period from 17-Feb-2004 to 16-May-2007; B) farm B: total samples $=555$, average number of samples per sampling $=28$, study period from 22-Mar-2004 to 4-Dec-2006; C) farm C: total samples $=277$, average number of samples per sampling $=31$, study period from 15 -Nov-2004 to 13-Nov-2006. 
February 2004 in farm A, 1 of 10 fecal samples cultured was positive for Salmonella Senftenberg. The only culture-positive sample in the second full herd sampling at this farm on October 2004 was determined to contain Salmonella Mbandaka. On farm B, at the first full herd sampling in March 2004, only 1 sample was found positive with Salmonella Typhimurium var. Copenhagen. At the next full herd sampling in September 2004, Salmonella Kentucky was found in 1 individual animal fecal sample and Salmonella Cerro was found in 45 individual animal fecal samples. A more frequent full herd sampling schedule was implemented at this farm to capture the course of the Salmonella outbreak. Cerro was the predominant serotype identified and $98 \%$ of Salmonella-positive animals were shedding Salmonella Cerro.

The prevalence of Salmonella in various environmental samples is in Figure 2. None of the 10 environmental samples collected in March 2004 from farm B (beginning of the study for this farm) were positive for Salmonella. Beginning in June 2004, 45 to 50 environmental samples were collected from farm B weekly for $4 \mathrm{wk}$ in response to the presence of clinical salmonellosis. During the first week, Salmonella Typhimurium var. Copenhagen (4 samples) was recovered, whereas in the second week, Salmonella Typhimurium var. Copenhagen (2 samples) and Salmonella Kentucky (1 sample) were recovered. By the third week, Salmonella Typhimurium var. Copenhagen (2 samples) and Salmonella Kentucky (10 samples) were recovered, and during the final week, only Salmonella Kentucky was isolated from 1 sample. The isolates came primarily from composite manure samples. The prevalence of different serovars of Salmonella isolated from samples in the summer of 2004 as well as from the second full herd sampling in September 2004 is presented in a separate box in Figure 2. Manure composites and drinking water were the major nonfecal sources from which Salmonella was isolated on farm B, and source water from this farm was never positive for Salmonella (Table 2). On farm B, 58.1\% (193 of 332) of manure composites and $40.4 \%$ (59 of 146) of drinking water samples were positive for Salmonella. Additionally, results from fecal and environmental samples from this farm indicated that Salmonella Typhimurium var. Copenhagen and Salmonella Kentucky were initially recovered, whereas Salmonella Cerro persisted in the herd at high prevalence. Salmonella was not isolated from farm A environmental samples, except for 1 manure composite sample in June 2004 and another manure composite sample from the pit in October 2004. On farm C, Salmonella was isolated at only 2 sampling times: November 2006 and May 2007 (Figure 2), and $7.5 \%$ (15 of 199) of the total manure composites were Salmonella-positive.

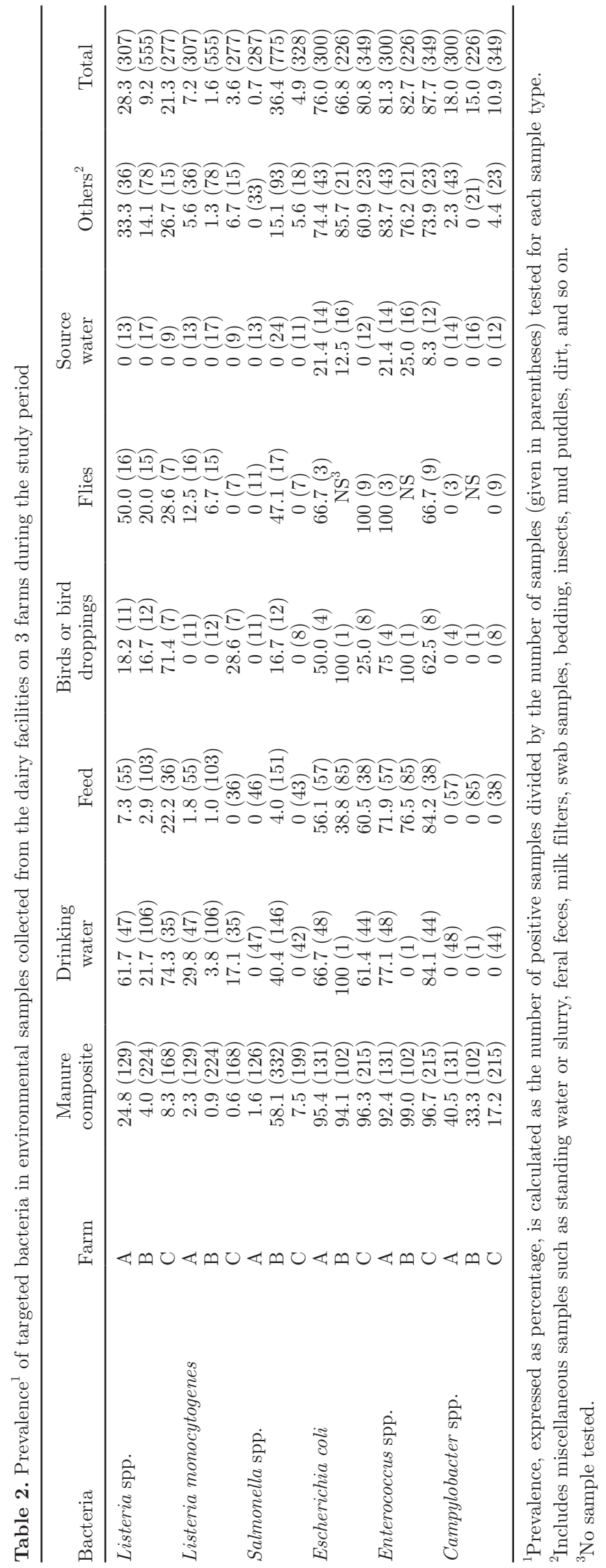

Journal of Dairy Science Vol. 92 No. 4, 2009 
Table 3. Prevalence ${ }^{1}$ of Salmonella spp. in fecal samples collected from dairy cows on 3 farms over the study period

\begin{tabular}{|c|c|c|c|c|}
\hline Farm & Sampling date & Sample collected $\left(\mathrm{n}_{\mathrm{c}}\right)^{2}$ & Sample tested $\left(\mathrm{n}_{\mathrm{t}}\right)^{3}$ & Salmonella spp. \\
\hline \multirow[t]{7}{*}{ A } & 17-Feb-2004 & 308 & 10 & 10.0 \\
\hline & 5-Oct-2004 & 326 & 1 & 100.0 \\
\hline & 12-Apr-2005 & 335 & 0 & $\mathrm{NA}^{4}$ \\
\hline & 3 -Oct- 2005 & 308 & 0 & NA \\
\hline & 1-May-2006 & 327 & 0 & NA \\
\hline & 9-Oct-2006 & 333 & 24 & 0.0 \\
\hline & 16-Apr-2007 & 333 & 0 & NA \\
\hline \multirow[t]{21}{*}{$\mathrm{B}$} & 22-Mar-2004 & 103 & 20 & 5.0 \\
\hline & 13-Sep-2004 & 110 & 110 & 41.8 \\
\hline & 27-Oct-2004 & 109 & 109 & 68.8 \\
\hline & 15-Dec-2004 & 108 & 108 & 59.3 \\
\hline & 24-Jan-2005 & 109 & 109 & 68.8 \\
\hline & 14-Mar-2005 & 111 & 111 & 66.7 \\
\hline & 25-Apr-2005 & 113 & 113 & 57.5 \\
\hline & 6-Jun-2005 & 111 & 111 & 29.7 \\
\hline & 1-Aug-2005 & 108 & 108 & 8.3 \\
\hline & 27-Sep-2005 & 102 & 102 & 28.4 \\
\hline & 4-Dec-2005 & 108 & 108 & 88.0 \\
\hline & 31-Jan-2006 & 122 & 122 & 72.1 \\
\hline & 27-Mar-2006 & 103 & 103 & 59.2 \\
\hline & 5-Jun-2006 & 104 & 104 & 83.7 \\
\hline & 7-Aug-2006 & 104 & 104 & 70.2 \\
\hline & 25-Sep-2006 & 102 & 102 & 68.6 \\
\hline & 4-Dec-2006 & 103 & 103 & 44.7 \\
\hline & 29-Jan-2007 & 110 & 110 & 72.7 \\
\hline & 27-Mar-2007 & 109 & 109 & 66.1 \\
\hline & 30-Apr-2007 & 112 & 112 & 67.9 \\
\hline & 5-Jun-2007 & 111 & 111 & 64.9 \\
\hline \multirow[t]{6}{*}{$\mathrm{C}$} & 15-Nov-2004 & 125 & 26 & 0.0 \\
\hline & 9-Мay-2005 & 134 & 0 & NA \\
\hline & 14-Nov-2005 & 132 & 0 & NA \\
\hline & 15-Мay-2006 & 168 & 0 & NA \\
\hline & 13-Nov-2006 & 141 & 141 & 2.8 \\
\hline & 21-May-2007 & 147 & 147 & 2.0 \\
\hline
\end{tabular}

${ }^{1}$ Prevalence is calculated as the number of positive samples divided by the number of samples tested $\left(\mathrm{n}_{\mathrm{t}}\right)$ expressed as percentage.

${ }^{2} \mathrm{n}_{\mathrm{c}}$ is the total number of individual fecal samples collected.

${ }^{3} \mathrm{n}_{\mathrm{t}}$ is the total number of samples used for microbial tests.

${ }^{4}$ Samples were not tested.

\section{E. coli, Enterococcus spp., and Campylobacter spp.}

The percentage of E. coli, Enterococcus, and Campylobacter in individual fecal samples is in Table 4. The prevalence of generic $E$. coli in fecal samples from these farms varied between 89 and $100 \%$ and enterococci between 75 and 100\%. The average prevalence of Campylobacter spp. in fecal samples from farm C was lower compared with the other 2 farms, although Campylobacter was not isolated from any fecal sample during 2 sampling times (April 2005 and May 2006) on farm A and 1 sampling time (June 2007) on farm B. The prevalence of E. coli, Enterococcus, and Campylobacter in environmental samples is in Figure 3; a similar pattern can be observed for these bacteria in each of the 3 farms. Campylobacter spp. was not isolated in any of the environmental samples during 2, 5, and 3 sampling times on farm A, B, and C, respectively. In addition to feces, these 3 organisms were detected mostly in manure composite samples collected from different locations in each farm. Campylobacter spp. was never detected in the source water collected from the 3 farms (Table 2).

\section{MAP}

The prevalence of MAP in individual dairy cows for the 3 study herds is in Table 5 . On farm A, prevalence of MAP-positive cows ranged from 1.5 to $3.2 \%$ and from 0.9 to $3.1 \%$ as obtained from fecal culture and ELISA analyses, respectively. Cows that were MAP-positive for both fecal culture and ELISA tests ranged from 0.6 to $1.6 \%$ in farm A. Fecal culture analysis showed that $6.8 \%$ of cows on farm B were positive for MAP in March 2004 followed by a decrease in prevalence to $<1 \%$ for the remainder of the study period. Cows that were MAP-positive by ELISA (seropositive) ranged from 0 to $2.9 \%$ and 0 to $1.9 \%$ of cows were positive for both tests on farm B. On farm C, MAP-positive cows 


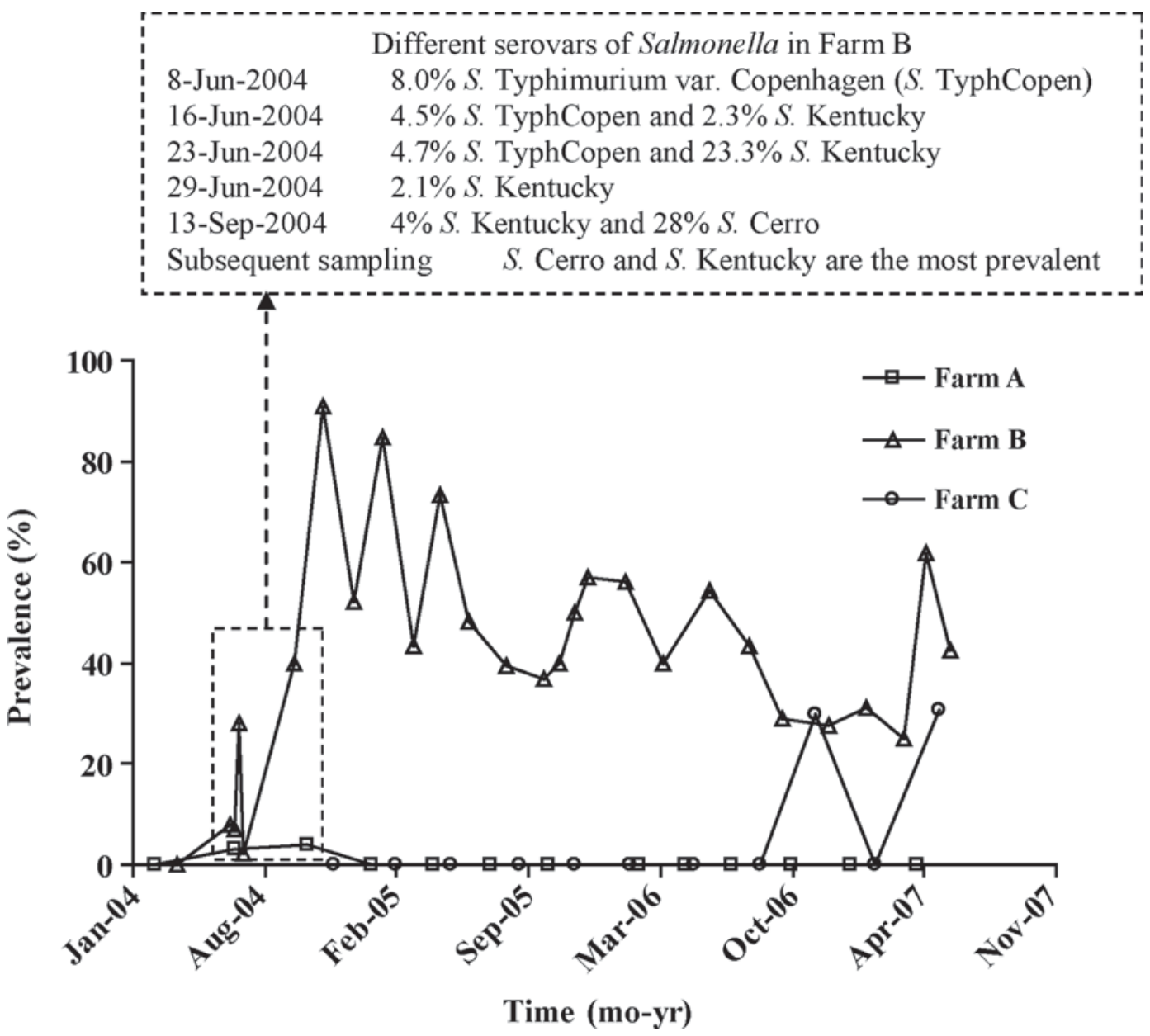

Figure 2. Prevalence of Salmonella spp. in environmental samples from 3 farms. A) farm A: total samples $=287$, average number of samples per sampling $=22$, study period from 17 -Feb-2004 to 16 -Apr-2007; B) farm B: total samples $=775$, average number of samples per sampling $=$ 29 , study period from 22-Mar-2004 to 5-Jun-2007; C) farm C: total samples $=328$, average number of samples per sampling $=30$, study period from 15-Nov-2004 to 21-May-2007.

ranged from 1.7 to $13.6 \%$ and from 1.4 to $4.9 \%$ from fecal culture and ELISA results, respectively. Cows that were MAP-positive for both tests ranged from 0.7 to $3.0 \%$ on farm C. Correlation between the number of seropositive and culture-positive animals was $\mathrm{r}=$ 0.61. Six animals (ID 1078, 1085, 1148, 1160, 1181, and 1200) on farm A and 5 animals (ID 66, 106, 114, 120 , and 164) on farm $\mathrm{C}$ that were culture-positive and seronegative became seropositive in subsequent visits. One animal each on farm A (ID 1637) and farm C (ID 216) that was identified as seropositive and culturenegative became culture-positive later in the study. On farm B, none of the animals that were culture-positive and seronegative became seropositive or vice versa in subsequent visits.

For farm A, out of 10 culture-positive animals at visit 1, 4 (40\%) were already culled at visit 2, $4(40 \%)$ were identified as culture-positive, and 2 (20\%) were culture-negative. On farm B, among 7 culture-positive animals at visit 1, $1(14.3 \%)$ was already culled at visit $2,1(14.3 \%)$ was culture-positive, and $5(71.4 \%)$ were culture-negative. Similarly, on farm C, out of 17 culture-positive cows during visit 1, $3(17.6 \%)$ animals were already culled at visit $2,4(23.5 \%)$ were culturepositive, and $10(58.8 \%)$ were culture-negative.

Based on fecal culture and ELISA results it was found that animal 1180 on farm A was consistently MAP-positive from the February 2004 sampling until the October 2005 sampling, with a maximum fecal concentration of $1.68 \times 10^{5} \mathrm{cfu}$ of $\mathrm{MAP} / \mathrm{g}$. This animal was eventually culled on January 17, 2006, because of clinical Johne's disease. Similarly, animal 1179 from farm A was MAP-positive from the October 2004 sampling to July 2006, and was subsequently culled on July 31 , 2006. In the first 3 samplings at farm B, animal 51 was positive for MAP and was continuously shedding 
Table 4. Prevalence ${ }^{1}$ of Escherichia coli, Enterococcus spp., and Campylobacter spp. in fecal samples collected from dairy cows on 3 farms over the study period

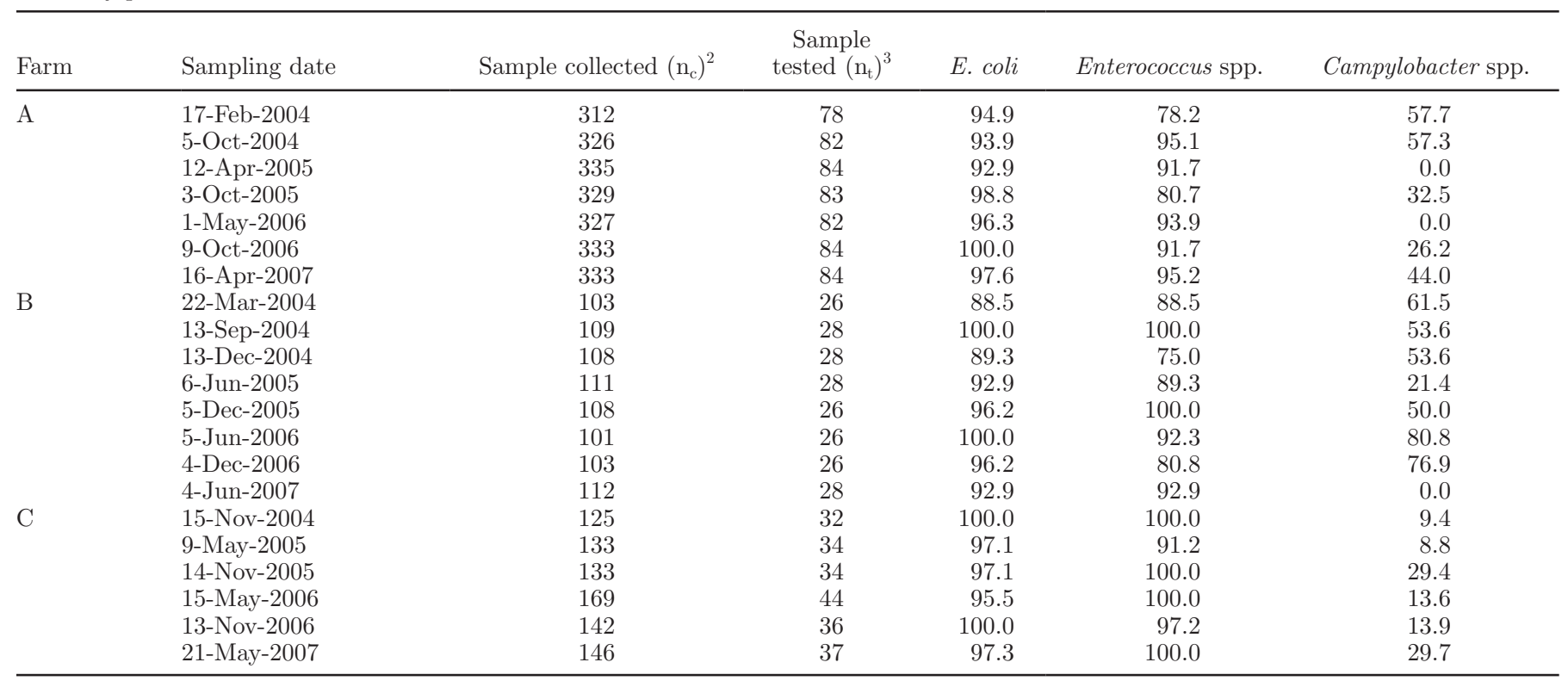

${ }^{1}$ Prevalence is calculated as the number of positive samples divided by the number of samples tested $\left(\mathrm{n}_{\mathrm{t}}\right)$ expressed as percentage.

${ }^{2} \mathrm{n}_{\mathrm{c}}$ is the total number of individual fecal samples collected.

${ }^{3} \mathrm{n}_{\mathrm{t}}$ is the total number of samples used for microbial tests. Samples collected from about every 4 th cow were used for the microbial test; that is, about $25 \%$ of total fecal samples collected were used for microbial analysis.

high numbers of MAP in the feces with a maximum of $7.42 \times 10^{5} \mathrm{cfu} / \mathrm{g}$ at the September 2004 sampling. This animal was subsequently culled on October 27, 2004. On farm C, animal 66 tested positive for MAP based on both fecal culture and ELISA tests from February 2005 to May 2006 and was culled on June 15, 2006. Fecal samples from this animal showed a maximum concentration of $2.38 \times 10^{5} \mathrm{cfu}$ of MAP/g at the May 2006 sampling.

The birth dates of MAP-positive cows in the 3 farms (positive at least once during the stay period in the farm) are shown in Figure 4 in a time-line fashion. This graph provides an indication of birth-cohort infections. As an example, the cow identifications and birth dates for 2 such clusters are highlighted in 2 dotted boxes for farm A. Cows 1179, 1180, 1181, and 1182 were all positive for MAP and were all born in November 2000. Two cows, 50 and 51 on farm B, were born on the same day (December 01, 1999) and both were positive for MAP. Similarly, on farm C, 2 cows (493 and 495) were positive for MAP and were both born on January 01, 2000.

\section{DISCUSSION}

Our results indicate that endemic infectious disease agents with zoonotic potential are common in dairy animals and their environments. The data show that major bacterial pathogens of animal and human importance associated with these zoonotic diseases were found on our study farms, but their presence was variable both within and between farms. The prevalence of Listeria spp. and L. monocytogenes in individual animal fecal samples ranged from 0 to $68.2 \%$ and 0 to $25.5 \%$, respectively, on farm A over a period of 3 yr (longitudinal study is still in progress). It was reported that fecal samples from healthy cattle frequently contain $L$. monocytogenes and its prevalence ranges from 3.1 to 51\% (Skovgaard and Morgen, 1988; Nightingale et al., 2004). Further, cattle may contribute to amplification and dispersal of L. monocytogenes into the farm environment. The bovine farm ecosystem frequently maintains a high prevalence of $L$. monocytogenes (Nightingale et al., 2004).

In our study, continuous shedding of Salmonella in individual fecal samples was observed on farm B with a prevalence ranging from 8 to $88 \%$ after the identification of a Salmonella Cerro outbreak in September 2004. In this farm, prevalence of Salmonella Typhimurium var. Copenhagen declined within 3 mo, whereas that of Salmonella Kentucky increased. Cerro ultimately supplanted these 2 serotypes in individual animals and the environment and persisted in the herd at high prevalence (Van Kessel et al., 2007). The prevalence of Salmonella in the United States as estimated from the 1996 and 2002 National Animal Health Monitoring 

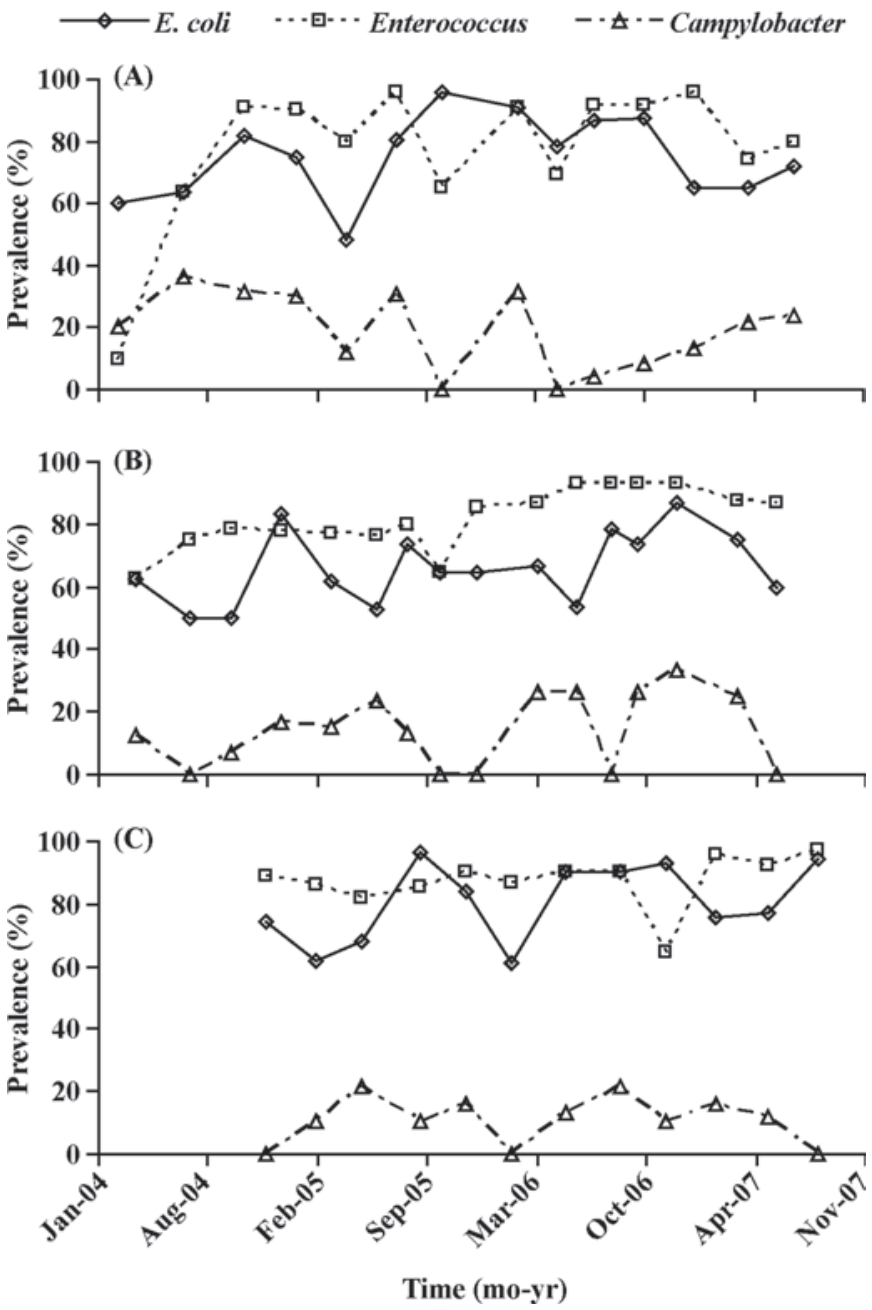

Figure 3. Prevalence of Escherichia coli, Enterococcus, and Campylobacter spp. in environmental samples from 3 farms. A) farm A: total samples $=300$, average number of samples per sampling $=$ 21, study period from 17-Feb-2004 to 9-Jul-2007; B) farm B: total samples $=226$, average number of samples per sampling $=14$, study period from 22-Mar-2004 to 4-Jun-2007; C) farm C: total samples = 349 , average number of samples per sampling $=29$, study period from 15-Nov-2004 to 20-Aug-2007.

Systems (NAHMS) dairy surveys was 27.5 and $31 \%$, respectively (USDA-APHIS, 2005). Additionally, in a multi-state survey, Salmonella spp. were isolated from $>90 \%$ of dairy farms, $4.8 \%$ of fecal samples, and $5.9 \%$ of environmental samples from 110 organic and conventional dairy farms in Minnesota, Wisconsin, Michigan, and New York State (Fossler et al., 2004).

Although Campylobacter spp. can be considered commensal organisms (Wesley et al., 2000) or normal flora in cattle, they may cause abortion, infertility, and embryonic death in cows and lead to diarrhea in newborn calves. Foodborne transmission of Campylobacter can occur through fecal contamination of milk or water or of carcasses at slaughter (USDA-APHIS, 2003). The prevalence rates for Campylobacter in cattle vary from 5 to $89.4 \%$ (Harvey et al., 2004) and Campylobacter jejuni and Campylobacter coli in dairy cattle range from 5 to $53 \%$ (Wesley et al., 2000), depending on methods of isolation (direct plating or enrichment), age of animal (calf or adult), season, and sample analyzed (feces or intestinal contents). The prevalence of Campylobacter spp. on the 3 study farms was different, with average prevalence higher on farm B (0 to 81\%) and lower on farm C (9 to 30\%). The percentage of Campylobacterpositive fecal samples on farm A was as high as $58 \%$ for 2 sampling times in 2004. Previous estimates of $C$. jejuni in dairy cows range from 0.8 to $100 \%$ (Wesley et al., 2000). The NAHMS Dairy 1996 study determined that 80.6 and $19.4 \%$ of dairy operations were positive for $C$. jejuni and $C$. coli, respectively, by a multiplex PCR assay. In the same study, approximately $38 \%$ of dairy cows had fecal samples positive for $C$. jejuni, and $1.8 \%$ were positive for $C$. coli. Results from NAHMS Dairy 2002 showed that the percentage of cows shedding Campylobacter spp. and the percentage of dairy herds with at least 1 cow shedding Campylobacter were 51.4 and $97.9 \%$, respectively, as determined through fecal cultures (USDA-APHIS, 2003). Wesley et al. (2000) detected C. jejuni and C. coli in 37.7 and $1.8 \%$ of fecal samples, respectively, by using PCR assays.

Different species of Enterococcus were isolated from feces of ruminants including beef cattle and dairy cows (Franz et al., 1999). Escherichia coli were isolated from a total of $95.8 \%$ of the samples and $100 \%(\mathrm{n}=97)$ of dairy operations (Lundin et al., 2008). As expected, the high prevalence of these commensal bacteria, E. coli and enterococci, in the 3 study farms indicated their widespread nature.

Murinda et al. (2004) collected swab, liquid, and solid dairy farm environmental samples from 4 dairy farms in 2002 to 2003 (165 to 180 per farm, a total of 691 samples). Campylobacter jejuni, Salmonella spp., and L. monocytogenes, respectively, were isolated from 5.06, 3.76 , and $6.51 \%$ of samples evaluated. The observation of a higher percentage of individual fecal and environmental samples positive for Listeria spp. on farm A and for Salmonella on farm B indicated their consistent presence and possible persistence on these farms, further emphasizing the implementation of necessary on-farm pathogen control approaches.

Five to $10 \%$ of animals typically test positive for MAP on infected farms (Benedictus et al., 2008), whereas shedding of high numbers of the organism ( $>100 \mathrm{cfu} / \mathrm{g}$ of feces) was observed in $<20 \%$ of animals (Mitchell et al., 2008). Fecal culture and ELISA results from the 3 study farms indicated a low prevalence of MAP carriage. Nevertheless, culture results showed the occasional presence of animals that shed very high 
numbers of MAP (>300 cfu/g). These animals were all eventually culled. Producers were aware of test results and followed the policy of culling high shedding (MAP) animals as they were no longer economical for milk production; no specific action was taken for low shedding animals. Future studies to determine the relationship between MAP shedding levels and maintenance in herds will be helpful to further elucidate the MAP bio-burden (culture loads) in the herds and the duration of MAP-positive cows staying in the herds. This type of longitudinal study would provide health status information of individual cows in a herd that would help the producers in their decision-making process of managing the farm animals and their environment.
The sensitivity of the ELISA tests depend on the population (stage of infection) of cattle tested (Collins et al., 2005). Despite low sensitivity of serum antibody diagnostic tests (Collins et al., 2005), these low-cost tests are most effective for commercial dairy herds, provided appropriate measures are taken based on ELISA results. The results obtained for this study, which employed a single, commercially available ELISA test (ParaCheck), may not be same for other assays that employ different antigens or otherwise differ in performance. Nonetheless, in Collins et al. (2005), agreement between the ELISA test used in this study and 4 other ELISA assays [HerdCheck (IDEXX Laboratories, Westbrook, ME), Pourquier (Institut Pourquier, Mont-

Table 5. Prevalence ${ }^{1}$ of Mycobacterium avium ssp. paratuberculosis-positive cows on 3 dairy farms over the study period

\begin{tabular}{|c|c|c|c|c|c|}
\hline Farm & Sampling date & $\begin{array}{l}\text { Sample } \\
\text { tested }\left(\mathrm{n}_{\mathrm{t}}\right)\end{array}$ & $\begin{array}{l}\text { Fecal culture } \\
\text { positive, } \mathrm{n}(\%)\end{array}$ & $\begin{array}{c}\text { ELISA positive, } \\
\mathrm{n}(\%)\end{array}$ & $\begin{array}{c}\text { Fecal culture and } \\
\text { ELISA positive, n (\%) }\end{array}$ \\
\hline \multirow[t]{13}{*}{$\mathrm{A}$} & 17-Feb-2004 & 312 & $10(3.21)$ & $7(2.24)$ & $5(1.60)$ \\
\hline & 17-Jun-2004 & 313 & -2 & $8(2.56)$ & \\
\hline & 5-Oct-2004 & 326 & $10(3.07)$ & $10(3.07)$ & $5(1.53)$ \\
\hline & 11-Jan-2005 & 345 & - & $9(2.61)$ & \\
\hline & 12-Apr-2005 & 335 & $7(2.09)$ & $5(1.49)$ & $2(0.60)$ \\
\hline & 11-Jul-2005 & 324 & - & $6(1.85)$ & \\
\hline & 3 -Oct-2005 & 329 & $10(3.04)$ & $4(1.22)$ & $3(0.91)$ \\
\hline & 20-Feb-2006 & 321 & - & $5(1.56)$ & \\
\hline & 1-May-2006 & 327 & $6(1.83)$ & $4(1.22)$ & $2(0.61)$ \\
\hline & 10-Jul-2006 & 336 & - & $4(1.19)$ & \\
\hline & $9-$ - ct-2006 & 333 & $5(1.50)$ & $3(0.90)$ & $3(0.90)$ \\
\hline & 8-Jan-2007 & 329 & - & $\mathrm{NA}^{3}$ & \\
\hline & 16-Apr-2007 & 333 & $10(3.00)$ & $5(1.5)$ & $4(1.20)$ \\
\hline \multirow[t]{14}{*}{ B } & 22-Mar-2004 & 103 & $7(6.80)$ & $3(2.91)$ & $2(1.94)$ \\
\hline & 28-Jun-2004 & 104 & - & $2(1.92)$ & \\
\hline & 12-Sep-2004 & 109 & $2(1.83)$ & $1(0.92)$ & $1(0.92)$ \\
\hline & 15-Dec-2004 & 108 & $0(0)$ & $0(0)$ & \\
\hline & 15-Mar-2005 & 111 & - & $0(0)$ & \\
\hline & 6-Jun-2005 & 111 & $1(0.9)$ & $0(0)$ & \\
\hline & 26-Sep-2005 & 102 & - & $0(0)$ & \\
\hline & 5-Dec-2005 & 108 & $0(0)$ & $0(0)$ & \\
\hline & 27-Mar-2006 & 103 & - & $0(0)$ & \\
\hline & 5-Jun-2006 & 102 & $1(0.98)$ & $0(0)$ & \\
\hline & 25-Sep-2006 & 104 & - & $0(0)$ & \\
\hline & 4 -Dec-2006 & 103 & $1(0.97)$ & $1(0.97)$ & $0(0)$ \\
\hline & 26-Mar-2007 & 112 & - & NA & \\
\hline & 4-Jun-2007 & 112 & $1(0.89)$ & $0(0)$ & \\
\hline \multirow[t]{11}{*}{$\mathrm{C}$} & 15 -Nov-2004 & 125 & $17(13.6)$ & $2(1.60)$ & $2(1.6)$ \\
\hline & 14-Feb-2005 & 123 & - & $2(1.63)$ & \\
\hline & 9-May-2005 & 133 & $7(5.26)$ & $4(3.01)$ & $4(3.01)$ \\
\hline & 22-Aug-2005 & 142 & - & $7(4.93)$ & \\
\hline & 14-Nov-2005 & 133 & $5(3.76)$ & $4(3.01)$ & $3(2.26)$ \\
\hline & 6-Feb-2006 & 143 & - & $3(2.10)$ & \\
\hline & 15-May-2006 & 175 & $3(1.71)$ & $5(2.86)$ & $2(1.14)$ \\
\hline & 21-Aug-2006 & 160 & - & $3(1.88)$ & \\
\hline & 13-Nov-2006 & 142 & $7(4.93)$ & $2(1.41)$ & $1(0.70)$ \\
\hline & $12-F e b-2007$ & 154 & - & NA & \\
\hline & 21-May-2007 & 147 & $5(3.4)$ & $2(1.36)$ & $1(0.68)$ \\
\hline
\end{tabular}

${ }^{1}$ Prevalence is calculated as the number of positive samples divided by the total number of samples tested $\left(\mathrm{n}_{\mathrm{t}}\right)$ expressed as percentage. All samples collected were tested for Mycobacterium avium ssp. paratuberculosis.

${ }^{2}$ No fecal samples were collected for fecal culture test; only blood samples were collected for ELISA testing on that sampling day.

${ }^{3}$ Samples were not tested. 

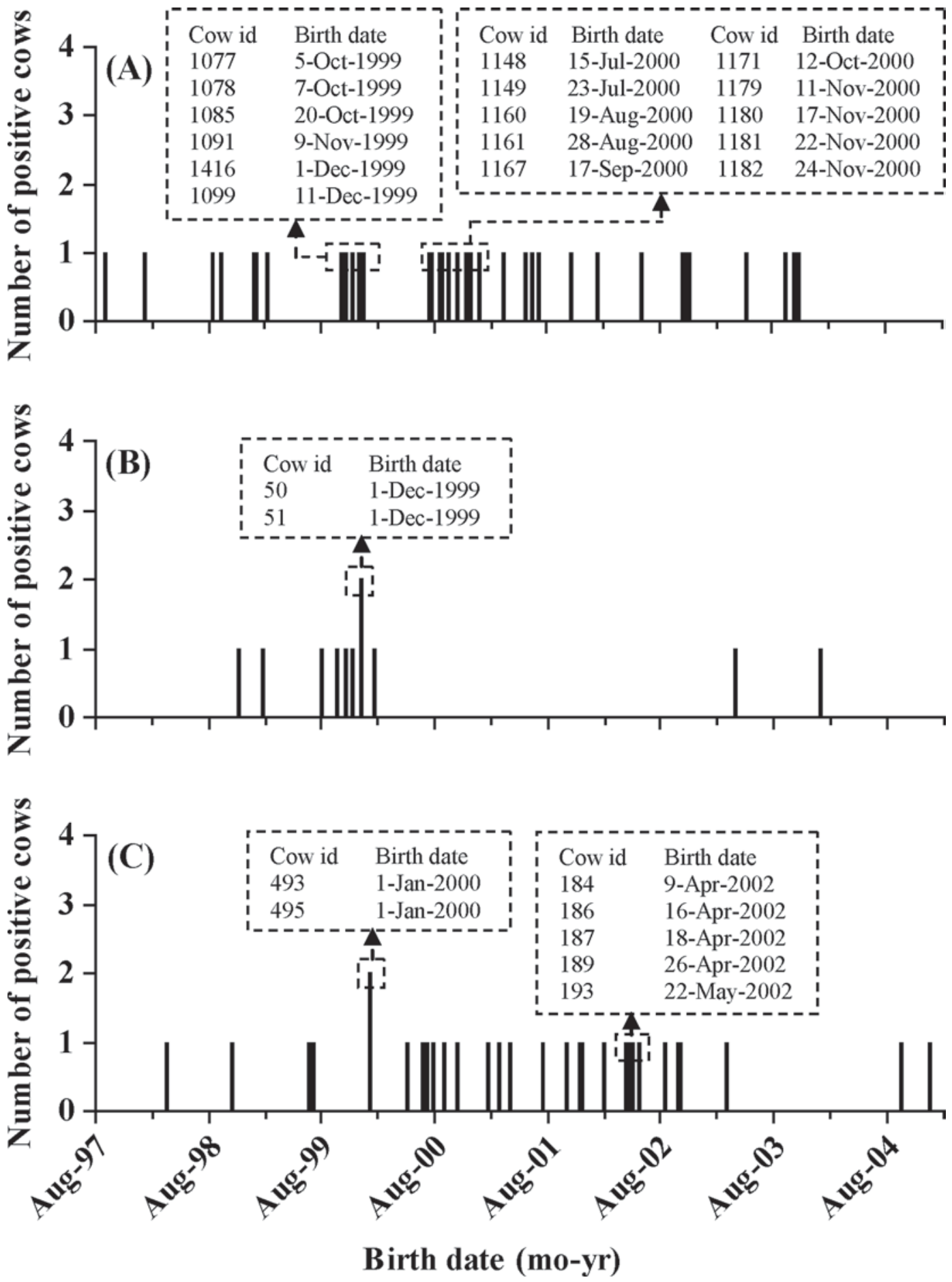

Figure 4. Timeline showing birth dates of Mycobacterium avium ssp. paratuberculosis (MAP)-positive cows as obtained from fecal culture results of 3 farms: A) farm A: a total of 38 positive cows; B) farm B: a total of 11 positive cows; and C) farm C: a total of 33 positive cows during the study period as presented in Table 5.

pellier, France), SERELISA ParaTB (Synbiotic Corp., San Diego, CA), and AntelBio (Antel Biosystems Inc., Lansing, MI)] for diagnosis of bovine paratuberculosis was 77.4 to $92.3 \%$. Diagnosis of Johne's disease was dif- ficult because many infected animals (up to $90 \%$ ) may show no signs at the time of sample collection and there is a lack of sensitive and specific assays that detect MAP early during infection (Bannantine et al., 2008). 
In contrast to prevailing dogma, it was suggested that tests for MAP-specific antibody such as ELISA-based assays that detect antibodies to lipoarabinomannan antigen, may provide early diagnosis of MAP-infected cattle (Bannantine et al., 2008). Additionally, these tests may be more sensitive than currently available commercial diagnostic tests. The test results obtained from experimentally infected cattle (Bannantine et al., 2008) after further evaluation with naturally infected animals in the field trials may be very helpful for incorporation into a diagnostic test for Johne's disease.

Considering the number of cows that were fecal culture-positive for MAP at least once and the total number of cows that were born during a 6 -yr period from the start of 1998 to the end of 2003, a rough calculation of expected probability of fecal shedding on farms A, $\mathrm{B}$, and $\mathrm{C}$ was 7,6 , and $13 \%$, respectively. Given the number of births per month, these probabilities lead to significant clusters when 3 or more MAP shedders are born in a given month on farm $\mathrm{A}$ and more than 1 shedder is born in a given month on farms B and C. These birth clusters are in Figure 4. In the period preceding the onset of clinical symptoms, infected animals may intermittently shed large quantities of MAP in their feces, milk, and colostrum. This subclinical shedding is generally thought the main factor in maintaining MAP infection in farms in addition to environmental contribution. Mycobacterium avium ssp. paratuberculosis can survive for up to a year in the environment and can persist for a limited period of time in the absence of susceptible individuals (Schukken et al., 2007).

Previous studies (Wesley et al., 2000; Murinda et al., 2004) on preharvest prevalence of foodborne pathogens focused on one-time-point sampling. Although these investigations provided point prevalence of the pathogens, longitudinal studies conducted concurrently in multiple farms in different geographical areas, such as the one described here, are necessary to provide insight into the dynamics of endemic infectious diseases in dairy herds. It is recognized that endemic infectious diseases are continuously present in the population and elimination of these diseases is not feasible, and in some cases, may be very difficult or impossible (Schukken et al., 2007). Nevertheless, a detailed understanding of the infection process and mechanism for persistence is essential to controlling these infections and lowering their incidence and prevalence in the dairy herds. Intensive longitudinal data are indispensable either to describe precisely the outbreak and subsequent endemic infection of a pathogen in dairy farms such as Salmonella in a Pennsylvania dairy farm (Van Kessel et al., 2007) or to describe the transmission dynamics and evaluate the persistence of pathogens in dairy farms through mathematical models (Benedictus et al., 2008; Mitchell et al., 2008). Bene- dictus et al. (2008) used the data from a unique set of animals within one well-managed dairy herd that was followed over a period of approximately $20 \mathrm{yr}$ to study the transmission dynamics of MAP infection, which is a disease of slow progression. These longitudinal data indicated that calves born shortly following the calving of an infected dam and calves growing up with a future high shedder were more likely infected compared with calves without this risk profile.

In the present study, using similar sampling and culture techniques on multiple farms, there was a difference in the prevalence (lower vs. higher levels) of zoonotic pathogens (including MAP) between farms. The reasons for variations in the prevalence of these pathogens from farm to farm are currently unknown, but may be related to many factors involving farm management, genetics, and nutrition (i.e., exposure, feed types, housing, hygiene condition, and manure management practices). Most bacteria were isolated directly from individual fecal samples; however, composite manure samples, drinking water as presented to cattle, feed, and other vectors (e.g., flies, insects, birds, and feral animals) constituted other areas of concern on these dairy farms. Some of these sources may be defined as critical control points on the dairy farms where pathogen reduction programs can be introduced. The use of preharvest intervention strategies at multiple critical points could control the presence of pathogens in dairy farms.

These data showing the prevalence of pathogens are relevant for pathogen control or eradication through better management and mitigation strategies. Callaway et al. (2003) discussed several potential preharvest intervention strategies (e.g., vaccination, competitive exclusion, the exploitation of the physiology of specific pathogens, and the use of antibiotics) to reduce foodborne pathogens in food animals. The presence of pathogens in the environmental samples suggests interventions in the drinking water troughs at the pen level, good manure management practices, including control of feral animals and in ensuring dairy farm hygiene to prevent further dissemination into the food-chain.

Although infected animals and contaminated environments rarely appear to directly cause human infections, animal-derived food products that are not processed before consumption such as raw milk and other products that appear contaminated during processing, such as meats, represent direct links between human infections and pathogens in farm animals and farm environments. Borucki et al. (2004) compared the pulsed-field gel electrophoresis restriction enzyme digestion profiles of L. monocytogenes dairy farm-associated strains, milk, environmental, and bovine, to human sporadic and epidemic disease strains and found that $23 \%$ of human 
sporadic strains had electrophoresis patterns identical to farm isolates. Dairy farms may serve as a source of pathogens that are inadvertently introduced into food-processing environments and may subsequently be transferred into foods through postprocessing contamination.

\section{ACKNOWLEDGMENTS}

We express our appreciation to the farm owners and personnel that participated in the study both at the farms and in the laboratories. This project was supported in part by the USDA-Agricultural Research Service (Agreements 58-1265-3-155, 58-1265-3-156, 58-1265-3-158, and 58-1265-4-020) for the Regional Dairy Quality Management Alliance (RDQMA) and the Johne's Disease Integrated Program (JDIP, USDA contract 45105).

\section{REFERENCES}

Bannantine, J. P., D. O. Bayles, W. R. Waters, M. V. Palmer, J. R. Stabel, and M. L. Paustian. 2008. Early antibody response against Mycobacterium avium subspecies paratuberculosis antigens in subclinical cattle. Proteome Sci. 6:5.

Benedictus, A., R. M. Mitchell, M. Linde-Widmann, R. Sweeney, T. Fyock, Y. H. Schukken, and R. H. Whitlock. 2008. Transmission parameters of Mycobacterium avium subspecies paratuberculosis infections in a dairy herd going through a control program. Prev. Vet. Med. 83:215-227.

Borucki, M. K., J. Reynolds, C. C. Gay, K. L. McElwain, S. H. Kim, D. P. Knowles, and J. X. Hu. 2004. Dairy farm reservoir of Listeria monocytogenes sporadic and epidemic strains. J. Food Prot. 67:2496-2499.

Callaway, T. R., R. C. Anderson, T. S. Edrington, R. O. Elder, K. J. Genovese, K. M. Bischoff, T. L. Poole, Y. S. Jung, R. B. Harvey, and D. J. Nisbet. 2003. Preslaughter intervention strategies to reduce food-borne pathogens in food animals. J. Anim. Sci. 81(E Suppl.):E17-E23.

Collins, M. T., S. J. Wells, K. R. Petrini, J. E. Collins, R. D. Schultz, and R. H. Whitlock. 2005. Evaluation of five antibody detection tests for diagnosis of bovine paratuberculosis. Clin. Diagn. Lab. Immunol. 12:685-692.

Edrington, T. S., M. E. Hume, M. L. Looper, C. L. Schultz, A. C. Fitzgerald, T. R. Callaway, K. J. Genovese, K. M. Bischoff, J. L. McReynolds, R. C. Anderson, and D. J. Nisbet. 2004. Variation in the fecal shedding of Salmonella and E. coli O157:H7 in lactating dairy cattle and examination of Salmonella genotypes using pulsedfield gel electrophoresis. Lett. Appl. Microbiol. 38:366-372.

Fossler, C. P., S. J. Wells, J. B. Kaneene, P. L. Ruegg, L. D. Warnick, J. B. Bender, S. M. Godden, L. W. Halbert, A. M. Campbell, and A. M. G. Zwald. 2004. Prevalence of Salmonella spp. on conventional and organic dairy farms. J. Am. Vet. Med. Assoc. 225:567-573.

Franz, C. M. A. P., W. H. Holzapfel, and M. E. Stiles. 1999. Enterococci at the crossroads of food safety? Int. J. Food Microbiol. 47:124.

Gansheroff, L. J., and A. D. O'Brien. 2000. Escherichia coli O157:H7 in beef cattle presented for slaughter in the U.S.: Higher prevalence rates that previously estimated. Proc. Natl. Acad. Sci. USA 97:2959-2961.

Gollnick, N. S., R. M. Mitchell, M. Baumgart, H. K. Janagama, S. Sreevatsan, and Y. H. Schukken. 2007. Survival of Mycobacterium avium subsp. paratuberculosis in bovine monocyte-derived macrophages is not affected by host infection status but depends on the infecting bacterial genotype. Vet. Immunol. Immunopathol. 120:93-105.
Grant, I. R. 2005. Zoonotic potential of Mycobacterium avium ssp. paratuberculosis: The current position. J. Appl. Microbiol. 98:1282-1293.

Harvey, R. B., R. E. Drolesky, C. A. Sheffield, T. S. Edrington, T. R. Callaway, R. C. Anderson, D. L. J. Drinnon, R. L. Ziprin, H. M. Scott, and D. J. Nisbet. 2004. Campylobacter prevalence in lactating dairy cows in the United States. J. Food Prot. 67:14761479 .

Jackson, C. R., P. J. Cray, and J. B. Barrett. 2004. Use of a genus- and species-specific multiplex PCR for identification of enterococci. J. Clin. Microbiol. 42:3558-3565.

Lundin, J. I., D. A. Dargatz, B. A. Wagner, J. E. Lombard, A. E. Hill, S. R. Ladely, and P. J. Fedorka-Cray. 2008. Antimicrobial drug resistance of fecal Escherichia coli and Salmonella spp. isolates from United States dairy cows. Foodborne Pathog. Dis. 5:7-19.

Mitchell, R. M., R. H. Whitlock, S. M. Stehman, A. Benedictus, P. Chapagain, Y. T. Grohn, and Y. H. Schukken. 2008. Simulation modeling to evaluate the persistence of Mycobacterium avium subsp. paratuberculosis (MAP) on commercial dairy farms in the United States. Prev. Vet. Med. 83:360-380.

Murinda, S. E., L. T. Nguyen, H. M. Nam, R. A. Almeida, S. J. Headrick, and S. P. Oliver. 2004. Detection of sorbitol-negative and sorbitol-positive shiga toxin-producing Escherichia coli, Listeria monocytogenes, Campylobacter jejuni, and Salmonella spp. in dairy farm environmental samples. Foodborne Pathog. Dis. 1:97-104.

Nam, H. M., S. E. Murinda, L. T. Nguyen, and S. P. Oliver. 2004. Evaluation of universal pre-enrichment broth for isolation of Salmonella spp., Escherichia coli O157:H7, and Listeria monocytogenes from dairy farm environmental samples. Foodborne Pathog. Dis. 1:37-44.

Nightingale, K. K., Y. H. Schukken, C. R. Nightingale, E. D. Fortes, A. J. Ho, Z. Her, Y. T. Grohn, P. L. McDonough, and M. Wiedmann. 2004. Ecology and transmission of Listeria monocytogenes infecting ruminants and in the farm environment. Appl. Environ. Microbiol. 70:4458-4467.

Oliver, S. P., B. M. Jayarao, and R. A. Almeida. 2005. Foodborne pathogens in milk and the dairy farm environment: Food safety and public health implications. Foodborne Pathog. Dis. 2:115129

Schukken, Y. H., L. Green, and G. Medley. 2007. Epidemiology of endemic infectious diseases-Accept endemicity or eliminate? Pages 99-107 in Proc. Am. Assoc. Bovine Pract. (AABP), 40th Annual Convention, Vancouver, British Columbia, Canada. AABP, Frontier Printers Inc., Stillwater, OK.

Skovgaard, N., and C. A. Morgen. 1988. Detection of Listeria spp. in feces from animals, in feeds, and in raw foods or animal origin. Int. J. Food Microbiol. 6:229-242.

Stern, N. J., B. Wojton, and K. Kwiatek. 1992. A differentialselective medium and dry ice-generated atmosphere for recovery of Campylobacter jejuni. J. Food Prot. 55:514-517.

USDA-APHIS. 2003. Salmonella and Campylobacter on U.S. Dairy Operations. http://www.aphis.usda.gov/vs/ceah/ncahs/nahms/ dairy/dairy02/Dairy02SalCampy.pdf Accessed Feb. 15, 2008.

USDA-APHIS. 2005. Salmonella on U.S. Dairy Operations: Prevalence and antimicrobial drug susceptibility. http://www.aphis.usda.gov/ vs/ceah/ncahs/nahms/dairy/dairy02/Dairy02_Salmonella.pdf Accessed Feb. 15, 2008.

Van Kessel, J. S., J. S. Karns, D. R. Wolfgang, E. Hovingh, and Y. H. Schukken. 2007. Longitudinal study of a clonal, subclinical outbreak of Salmonella enterica subsp. enterica serovar Cerro in a US dairy herd. Foodborne Pathog. Dis. 4:449-461.

Wells, S. J., and B. A. Wagner. 2000. Herd-level risk factors for infection with Mycobacterium paratuberculosis in US dairies and association between familiarity of the herd manager with the disease or prior diagnosis of the disease in that herd and use of preventive measures. J. Am. Vet. Med. Assoc. 216:1450-1457.

Wesley, I. V., S. J. Wells, K. M. Harmon, A. Green, L. SchroederTucker, M. Glover, and I. Siddique. 2000. Fecal shedding of Campylobacter and Arcobacter spp. in dairy cattle. Appl. Environ. Microbiol. 66:1994-2000. 